\title{
Causes of Hospital Readmissions at the Community Level
}

\author{
Ronald Lagoe $^{1 *}$, Barbara Drapola ${ }^{2}$, Diane Nanno ${ }^{3}$, Shelly Littau ${ }^{1}$ \\ ${ }^{1}$ Hospital Executive Council, Syracuse, NY, USA \\ ${ }^{2}$ Crouse Hospital, Syracuse, NY, USA \\ ${ }^{3}$ State University of New York Upstate University Hospital, Syracuse, NY, USA \\ Email: ${ }^{\star H o s p e x c l @ c n y m a i l . c o m ~}$
}

How to cite this paper: Lagoe, R., Drapola, B., Nanno, D. and Littau, S. (2017) Causes of Hospital Readmissions at the Community Level. International Journal of Clinical Medicine, 8, 248-256.

https://doi.org/10.4236/ijcm.2017.84024

Received: March 29, 2017

Accepted: April 27, 2017

Published: April 30, 2017

Copyright (c) 2017 by authors and Scientific Research Publishing Inc. This work is licensed under the Creative Commons Attribution International License (CC BY 4.0).

http://creativecommons.org/licenses/by/4.0/

(c) (7) Open Access

\begin{abstract}
Reducing inpatient hospital readmissions has been an important component of efforts to improve outcomes and reduce health care costs. This study focused on evaluation of the clinical causes of hospital readmissions of adult medical/surgical patients within 30 days between October 2015 and September 2016. It was based on the principal diagnoses of readmissions, a definition that is used throughout the health care industry in the United States. The study focused on adult medicine and adult surgery readmissions in Syracuse, New York, a small metropolitan area, during a twelve month period. It included almost 4000 individual readmissions. The study data demonstrated that only about 22 percent of inpatient readmissions were for the same diagnoses as the initial admissions that preceded them. The study data also indicated that another 20 percent of hospital readmissions involved a diagnosis different from that of the initial admission but in the same body system. Most importantly, the study demonstrated that a consistent majority of inpatient readmissions were caused by diagnoses in different body systems than the initial. The data suggested that efforts to address the causes of hospital readmissions should be based on management of a broad range of adult medicine conditions, rather than individual diagnoses.
\end{abstract}

\section{Keywords}

Hospital Readmissions, Hospitalization, Hospital Outcomes

\section{Introduction}

Historically, improving the efficiency of health care has been a major concern in the United States. This subject has gained increased attention with efforts by the new administration in Washington to contain the costs of Medicaid and Medi- 
care. Both of these major payers could be addressed with limitations in federal funding [1] [2] [3].

In recent years, a recognition has developed that improvements in the efficiency and outcomes of care are linked. This recognition has stimulated the development of efforts to reduce adverse outcomes and related costs. Because of their high costs, the reduction of hospital readmissions has become an important focus of these efforts [4] [5] [6].

These initiatives have included the development of studies of factors related to readmissions. Researchers have developed models of readmissions that can predict these outcomes. These studies have produced much useful information, but have failed to develop models that can predict readmissions with a high degree of accuracy [7] [8].

These studies have substantially increased understanding of hospital inpatient readmissions. They have been supported by the development of computer tools that address these outcomes [9].

Through all of this research, one of the most important aspects of this subject has been the clinical causes of hospital readmissions. These causes involve broad ranges of diagnoses rather than individual conditions. Definition and understanding of them appear to be essential to progress in improving these outcomes [10].

\section{Population}

This study evaluated causes of inpatient readmissions within 30 days of the initial admission in the metropolitan area of Syracuse, New York. This area includes three large acute care facilities, Crouse Hospital (19,478 inpatient discharges excluding well newborns, 2016), St. Joseph's Hospital Health Center $(25,101$ discharges, 2016), and the State University of New York Upstate University Hospital (29,427 discharges, 2016). These hospitals have provided primary and secondary acute care to an immediate service area with a population of approximately 600,000 and tertiary services to the 11 county Central New York Health Service Area with a population of 1,400,000.

Historically, the Syracuse hospitals have maintained a relatively low inpatient admission rate, despite demographics that may contribute to increased readmission rates among disadvantaged populations. This rate has been comparable to those of metropolitan areas such as Rochester and Albany, New York that have higher managed care penetration [11].

The Syracuse hospitals have worked cooperatively to improve the efficiency and outcomes of care in the community through the Hospital Executive Council. These efforts have included the reduction of hospital lengths of stay and readmissions, as well as the development of subacute and complex care programs aimed at supporting efficient transitions of care for difficult to place patients. The readmissions program has been carried out in cooperation with $3 \mathrm{M}^{\mathrm{TM}}$ Health Information Systems. 


\section{Method}

This study evaluated clinical causes of inpatient readmissions in the hospitals of Syracuse, New York during a twelve month period. Economic and social determinants of health as potential causes of readmissions were not examined. It included more than 4000 individual adult medicine and adult surgery readmissions, 82.8 percent of the total, in the area's three acute hospitals [11]. It was based on simple descriptive statistics.

The study was carried out using patient specific data from each of the hospitals by the Hospital Executive Council. These data were obtained through Business Associate Agreements with each of the hospitals. The Council functions as a mechanism for the development of multihospital studies in the Syracuse metropolitan area.

Hospital readmissions were identified using the Potentially Preventable Readmissions system developed by $3 \mathrm{M}^{\mathrm{TM}}$ Health Information Systems. This software uses hospital administrative data to identify readmissions within 30 days of the initial admission and a number of clinical and demographic indicators for each patient.

Readmissions were identified for adult medicine and adult surgery patients using the All Patients Refined Diagnosis Related Group System (APR DRG). This system identifies the hospital service of each inpatient based on the principal diagnosis, secondary diagnoses, principal procedure, and other clinical and demographic characteristics.

For purposes of this study, the clinical cause of each inpatient readmission was identified as the All Patients Refined Diagnosis Related Group. This indicator is based on the principal diagnosis or principal procedure of the inpatient stay. The principal diagnosis is the condition, which in the opinion of the discharge abstractor, was the principal cause of the admission. The analysis also included Major Diagnostic Categories (MDCs) which are collections of APR DRGs by anatomical areas.

The first component of the analysis focused on clinical causes of inpatient adult medicine and adult surgery readmissions for the period October 2015September 2016. This was the latest time interval for which complete data were available.

Each of the readmissions was identified as one of three categories. The first was a return in the same APR DRG as the initial admission, such as a Chronic Obstructive Pulmonary Disease (COPD) patient returning for COPD. The second was a return in the same MDC as the initial admission but a different APR DRG, such as a COPD patient returning for pneumonia. The third category was a return in a different MDC than the initial admission, such as a COPD patient returning for a digestive disorder.

Numbers of readmissions were identified for each of the three categories by hospital and total. The data were generated for adult medicine and adult surgery readmissions for October-December 2015, January-March 2016, April-June 2016, and July-September 2016. Differences in numbers of readmissions and percen- 
tages of the adult medicine and adult surgery total among the three categories and for the combined population were identified.

The second component of the analysis focused on clinical causes of inpatient readmissions in the Syracuse hospitals for the third category, those who returned with a Major Diagnostic Category outside the MDC of the Initial Admission. These data were aggregated for each of the three month periods by MDC for the combined hospitals. Differences in numbers of readmissions by MDC were compared.

\section{Results}

The initial component of the study focused on identification of the clinical causes of a full range of readmissions for adult medicine and adult surgery in the Syracuse hospitals. The remaining readmissions were produced by obstetrics, pediatrics, and mental health services. Related data are summarized in Table 1.

Table 1. Potentially preventable readmissions within 30 days, medical/surgical patients-all Payors, Syracuse hospitals.

\begin{tabular}{|c|c|c|c|c|c|c|c|c|}
\hline & \multicolumn{4}{|c|}{ Number of Readmissions } & \multicolumn{4}{|c|}{ Percent of Total Readmissions } \\
\hline & $\begin{array}{l}\text { Crouse } \\
\text { Hospital }\end{array}$ & $\begin{array}{c}\text { St. Joseph's } \\
\text { Hospital } \\
\text { Health } \\
\text { Center }\end{array}$ & $\begin{array}{c}\text { State } \\
\text { University of } \\
\text { NY Upstate } \\
\text { University } \\
\text { Hospital }\end{array}$ & Total & $\begin{array}{l}\text { Crouse } \\
\text { Hospital }\end{array}$ & $\begin{array}{c}\text { St. Joseph's } \\
\text { Hospital } \\
\text { Health } \\
\text { Center }\end{array}$ & $\begin{array}{c}\text { State } \\
\text { University } \\
\text { of NY Upstate } \\
\text { University } \\
\text { Hospital }\end{array}$ & Total \\
\hline \multicolumn{9}{|c|}{ Readmissions to Same APR DRG } \\
\hline October-December 2015 & 29 & 72 & 71 & 172 & 15.5 & 18.7 & 21.6 & 19.1 \\
\hline January-March 2016 & 41 & 104 & 109 & 254 & 21.4 & 21.5 & 30.3 & 24.5 \\
\hline April-June 2016 & 45 & 75 & 103 & 223 & 20.5 & 17.0 & 27.2 & 21.5 \\
\hline July-September 2016 & 41 & 79 & 103 & 223 & 20.1 & 20.0 & 26.2 & 22.5 \\
\hline \multicolumn{9}{|c|}{ Readmissions to Same APR MDC } \\
\hline October-December 2015 & 40 & 95 & 61 & 196 & 21.4 & 24.6 & 18.5 & 21.7 \\
\hline January-March 2016 & 48 & 100 & 65 & 213 & 25.0 & 20.7 & 18.1 & 20.6 \\
\hline April-June 2016 & 48 & 107 & 64 & 219 & 21.8 & 24.4 & 16.9 & 21.1 \\
\hline July-September 2016 & 32 & 86 & 75 & 193 & 15.7 & 21.8 & 19.1 & 19.5 \\
\hline \multicolumn{9}{|c|}{ Readmissions to Different APR MDC } \\
\hline October-December 2015 & 118 & 219 & 197 & 534 & 63.1 & 56.7 & 59.9 & 59.2 \\
\hline January-March 2016 & 103 & 280 & 186 & 569 & 53.7 & 57.9 & 51.7 & 54.9 \\
\hline April-June 2016 & 127 & 257 & 212 & 596 & 57.7 & 58.5 & 55.9 & 57.4 \\
\hline July-September 2016 & 131 & 230 & 215 & 576 & 64.2 & 58.2 & 54.7 & 58.1 \\
\hline \multicolumn{9}{|l|}{ Total Readmissions } \\
\hline October-December 2015 & 187 & 386 & 329 & 902 & 100.0 & 100.0 & 100.0 & 100.0 \\
\hline January-March 2016 & 192 & 484 & 360 & 1,036 & 100.0 & 100.0 & 100.0 & 100.0 \\
\hline April-June 2016 & 220 & 439 & 379 & 1,038 & 100.0 & 100.0 & 100.0 & 100.0 \\
\hline July-September 2016 & 204 & 395 & 393 & 992 & 100.0 & 100.0 & 100.0 & 100.0 \\
\hline
\end{tabular}

Source: Hospital Executive Council. 
The data indicated that a total of 3968 adult medicine and adult surgery readmissions occurred in the Syracuse hospitals between October 2015 and September 2016. These rehospitalizations accounted for 83.2 percent of all inpatient readmissions in the hospitals during this period. The rest were produced by obstetrics, pediatrics, and mental health. Of the total adult medicine and adult surgery readmissions, 75.0 percent involved adult medicine patients.

The analysis was based on the causes of inpatient readmissions defined by the relationship between the principal diagnoses of the initial admissions and the readmissions. Three types of relationships between initial admissions and readmissions were identified.

The proportions of readmissions that occurred in the same Diagnosis Related Group as the initial admission comprised the most direct relationship between these hospitalizations. Most of these readmissions involved exacerbation of principal diagnoses of initial admissions for chronic diseases such as heart failure, chronic obstructive pulmonary disease, and digestive disorders. They accounted for 22.0 percent of the total medical-surgical readmissions for the 12 month period. They ranged from 15.5 to 21.4 percent of the adult medicine and adult surgery total at Crouse Hospital, 17.0 to 21.5 percent at St. Joseph's Hospital Health Center, and 21.6 to 30.3 percent at the State University of New York Upstate University Hospital.

A second group of rehospitalizations included patients who returned for a different principal diagnosis, defined by the Diagnosis Related Group, within the same body system, Major Diagnostic Category. Most of these readmissions occurred in Major Diagnostic Categories that generated large numbers of adult medicine readmissions such as the Respiratory, Circulatory, and Digestive classifications. They accounted for 20.7 percent of medical surgical readmissions for the combined hospitals during the 12 month period. On a quarterly basis, these patients comprised 15.7 to 25.0 percent of the adult medicine and adult surgery total at Crouse Hospital, 20.7 to 24.6 percent at St. Joseph's Hospital Health Center, and 16.9 to 19.1 percent at the State University of New York Upstate University Hospital.

For each hospital, a majority of inpatient adult medicine and adult surgery readmissions occurred in Major Diagnostic Categories different from those of the initial admission. These patients accounted for 57.3 percent of readmissions in the combined hospitals during the 12 month period. They included 53.7 to 64.2 percent of adult medicine and adult surgery total at Crouse Hospital, 56.7 to 58.5 percent of the total at St. Joseph's Hospital Health Center, and 51.7 to 59.9 percent of the total at Upstate University Hospital.

The second component of the study focused on the third category of the initial analysis, those patients in the Syracuse hospitals who returned for a cause of readmission in a Major Diagnostic Category different from that of the initial admission. Relevant data are summarized in Table 2.

This information demonstrated that these readmissions occurred in a wide range of Major Diagnostic Categories. In each three month period within the 
Table 2. Potentially preventable readmissions within 30 days, readmissions to different APR Major Diagnostic Category medi$\mathrm{cal} /$ surgical patients-all Payors, Syracuse hospitals.

\begin{tabular}{|c|c|c|c|c|c|c|c|c|c|}
\hline & & & Numbe & er of Readn & nissions & & & Percent of & Total \\
\hline & DC/Descrintion & October-December & January-March & April-June & July-September & October-December & January- & April-June & July-September \\
\hline & DU/Deschiption & 2015 & 2016 & 2016 & 2016 & 2015 & March 2016 & 2016 & 2016 \\
\hline 01 & Nervous System & 19 & 22 & 29 & 23 & 3.6 & 3.9 & 4.9 & 4.0 \\
\hline 03 & $\begin{array}{l}\text { Ear, Nose, } \\
\text { Throat, Mouth } \\
\text { \& Craniofacial }\end{array}$ & 2 & 1 & 1 & 1 & 0.4 & 0.2 & 0.2 & 0.2 \\
\hline 04 & $\begin{array}{l}\text { Respiratory } \\
\text { System }\end{array}$ & 88 & 98 & 94 & 86 & 16.5 & 17.2 & 15.8 & 14.9 \\
\hline 05 & $\begin{array}{l}\text { Circulatory } \\
\text { System }\end{array}$ & 69 & 68 & 79 & 62 & 12.9 & 12.0 & 13.3 & 10.8 \\
\hline 06 & Digestive System & 58 & 67 & 61 & 75 & 10.9 & 11.8 & 10.2 & 13.0 \\
\hline 07 & $\begin{array}{c}\text { Hepatobiliary } \\
\text { System \& } \\
\text { Pancreas }\end{array}$ & 12 & 8 & 15 & 8 & 2.2 & 1.4 & 2.5 & 1.4 \\
\hline 08 & $\begin{array}{c}\text { Musculoskeletal } \\
\text { System \& } \\
\text { Connective } \\
\text { Tissue }\end{array}$ & 10 & 12 & 10 & 8 & 1.9 & 2.1 & 1.7 & 1.4 \\
\hline 09 & $\begin{array}{c}\text { Skin, } \\
\text { Subcutaneous } \\
\text { Tissue \& Breast }\end{array}$ & 20 & 17 & 9 & 17 & 3.7 & 3.0 & 1.5 & 3.0 \\
\hline 10 & $\begin{array}{l}\text { Endocrine, } \\
\text { Nutritional \& } \\
\text { Metabolic }\end{array}$ & 34 & 35 & 43 & 48 & 6.4 & 6.2 & 7.2 & 8.3 \\
\hline 11 & $\begin{array}{c}\text { Kidney \& } \\
\text { Urinary Tract }\end{array}$ & 47 & 50 & 52 & 53 & 8.8 & 8.8 & 8.7 & 9.2 \\
\hline 16 & $\begin{array}{c}\text { Blood \& } \\
\text { Immunology } \\
\text { Disorders }\end{array}$ & 10 & 10 & 15 & 13 & 1.9 & 1.8 & 2.5 & 2.3 \\
\hline 18 & $\begin{array}{l}\text { Infectious \& } \\
\text { Parasitic } \\
\text { Diseases }\end{array}$ & 115 & 129 & 126 & 132 & 21.5 & 22.7 & 21.1 & 22.9 \\
\hline 21 & $\begin{array}{c}\text { Poison, } \\
\text { Toxic Effect \& } \\
\text { Other Injury }\end{array}$ & 35 & 35 & 38 & 39 & 6.6 & 6.2 & 6.4 & 6.8 \\
\hline 23 & $\begin{array}{l}\text { Rehabilitation, } \\
\text { Aftercare, } \\
\text { Other Health } \\
\text { Status }\end{array}$ & 15 & 17 & 24 & 11 & 2.8 & 3.0 & 4.0 & 1.9 \\
\hline & Total & 534 & 569 & 596 & 576 & 100.0 & 100.0 & 100.0 & 100.0 \\
\hline
\end{tabular}

Source: Hospital Executive Council.

Syracuse hospitals, a majority of these readmissions involved a combination of infectious diseases and adult medicine conditions such as respiratory, circulato- 
ry, and digestive disorders. During the twelve month period of the study, these four Major Diagnostic Categories were associated with 60.4 to 63.6 percent of readmissions that occurred outside the MDC of the initial admission.

The study data indicated that infectious diseases, MDC 18, were the single largest source of readmissions outside the original Major Diagnostic Category for each hospital and time period. Within this Major Diagnostic Category, sepsis was the major cause of readmissions. The data suggested that these diagnoses were related to readmissions and other utilization issues such as extended stays.

The study data also demonstrated that large numbers of readmissions that occurred outside the Major Diagnostic Category on the initial admission involved anatomical areas such as the respiratory, circulatory, and digestive systems that have been sources of most adult medicine hospital inpatient admissions and readmissions. Most of these conditions were present on the initial admissions as secondary diagnoses.

This portion of the study demonstrated that the largest percentages of medical and surgical readmissions involved more than one body system. The causes of these admissions were identified within the definition of adult medicine.

\section{Discussion}

The reduction of hospital inpatient readmissions has been a major focus of efforts to improve patient outcomes and reduce health care costs. Significant attention has been applied nationally to the management of chronic conditions such as heart failure, chronic obstructive pulmonary disease, and diabetes in hospitals in efforts to reduce recidivism. The complicated nature of readmissions suggests, however, that efforts to address them need to be accompanied by careful evaluation of a wide range of clinical causes rather than individual diagnoses.

This study focused on evaluation of the clinical causes of hospital readmissions of adult medical-surgical patients within 30 days of the admissions that preceded them. It was based on the principal diagnoses of readmissions. The principal diagnosis is defined as the condition that was responsible for each hospital admission. This is a definition that is used throughout the health care industry in the United States.

The study focused on adult medicine and adult surgery readmissions in the hospitals that comprised the acute care system of a small metropolitan area during a twelve month period. It included almost 4000 individual readmissions, approximately 83 percent of the community total.

The study data demonstrated that, at the aggregate and hospital specific levels, only about 22 percent of inpatient readmissions were for the same diagnosis as the initial admission that preceded them. The quarterly ranges of each of the three hospitals were consistent with this rate. The data suggested that the most direct relationship between initial admissions and readmissions existed for a minority of all adult medicine and adult surgery readmissions in the community.

The study data indicated that another 20 percent of hospital readmissions in the population involved a diagnosis different than that of the initial admission, 
but in the same body system. This meant that $40-45$ percent of readmissions involved the same anatomical area.

Perhaps most importantly, the study demonstrated that a slight but consistent majority of inpatient readmissions were caused by diagnoses in different body systems than the initial admission. This majority of readmissions appeared in the data for all three hospitals.

The Major Diagnostic Categories involved in this category suggested that most of these readmissions involved medical diagnoses of infectious disease, respiratory, circulatory, and digestive conditions. Many of these diagnoses were present on the initial admissions as secondary diagnoses. They involved conditions that are usually classified as internal medicine.

\section{Recommendations}

The study data suggested that efforts to address the causes of hospital inpatient readmissions should be based on the management of a broad range of adult medicine conditions rather than individual diagnoses. This approach will involve a much larger range of conditions than programs that narrowly address individual diagnosis such as heart failure or COPD.

This approach will take advantage of the clinical experience with connections among these conditions. This means that clinical managers of readmissions will need to be well versed in internal medicine. This background will prepare them for guiding the care of patients with issues in different body systems.

The same suggestion could be made to payers and regulators seeking to improve health care outcomes. Their efforts need to be based on clinical areas such as adult medicine, rather than individual diagnoses. As interest in improving health care outcomes continues to develop, this kind of approach holds promise for both consumers and providers of care.

\section{References}

[1] Dentzler, S. (2011) Urgent Measures for an Old Problem. Health Affairs, 30, 1626. https://doi.org/10.1377/hlthaff.2011.0961

[2] Meyer, H. (2017) President Trump's Healthcare Plate Is Full and It Won't Go Down Easy. Modern Healthcare, 47, 6-7.

[3] Dickson, V. and Meyer, H. (2017) New HHS Secretary Price Faces a Crushing Inbox. Modern Healthcare, 47, 6-7.

[4] Rau, J. (2014) Medicare Fines 2610 Hospitals in Third Round of Readmission Penalties. Kaiser Health News, 2 October 2014.

[5] Gorodeski, E.Z., Starling, R.C. and Blackstone, E.H. (2010) Are All Readmissions Bad Readmissions? The New England Journal of Medicine, 363, 297-298. https://doi.org/10.1056/NEJMc1001882

[6] Berensdon, R.A., Paulus, R.A. and Kalman, N.S. (2012) Medicare's Readmission Reduction Program: A Positive Alternative. The New England Journal of Medicine, 366, 1364-1366. https://doi.org/10.1056/NEJMp1201268

[7] Kansagara, D., Englander, H., Salantiro, A., Kagen, D., Theobald, C., Freeman, M. and Kripalani, S. (2011) Risk Prediction Models for Hospital Readmission: A Sys- 
tematic Review. JAMA, 306, 1688-1698. https://doi.org/10.1001/jama.2011.1515

[8] Grunier, A., Dhalla, A., van Walraven, C., Fisher, H.D., Camacho, X., Rochon, P.A. and Anderson, G.M. (2011) Unplanned Readmissions after Discharge among Patients Identified as Being at High Risk of Readmission Using a Validated Predictive Algorithm. Open Medicine, 5, e104-e111.

[9] Goldfield, N.J., McCullough, E.C., Hughes, J.S., Tang, A.M., Eastman, B., Rawlins, L.K. and Averill, R.F. (2008) Identifying Potentially Preventable Readmissions. Health Care Financing Review, 30, 75-92.

[10] Lagoe, R., Nanno, D. and Luziani, M. (2013) Clinical Identification of Patients Readmitted to Hospitals: Why Patients Return. BMC Research Notes, 6, 419. https://doi.org/10.1186/1756-0500-6-419

[11] Lagoe, R., Kronenberg, P. and Littau, S. (2016) Readmissions by Hospital Inpatient Service at the Community Level. Internal Medicine Review, 2.

Submit or recommend next manuscript to SCIRP and we will provide best service for you:

Accepting pre-submission inquiries through Email, Facebook, LinkedIn, Twitter, etc. A wide selection of journals (inclusive of 9 subjects, more than 200 journals)

Providing 24-hour high-quality service

User-friendly online submission system

Fair and swift peer-review system

Efficient typesetting and proofreading procedure

Display of the result of downloads and visits, as well as the number of cited articles Maximum dissemination of your research work

Submit your manuscript at: http://papersubmission.scirp.org/

Or contact ijcm@scirp.org 